\title{
HispanismeS
}

Revue de la Société des Hispanistes Français

\section{Lenguas cooficiales en una Cataluña multilingüe y lengua habitual en los usos particulares}

Les langues co-officielles dans une Catalogne multilingue et la langue usuelle dans l'usage privé

Co-official languages in a multilingual Catalonia and the language customary in private usage

\section{Mercé Pujol Berché}

\section{OpenEdition}

\section{Journals}

Edición electrónica

URL: https://journals.openedition.org/hispanismes/799

DOI: 10.4000/hispanismes.799

ISSN: 2270-0765

\section{Editor}

Société des Hispanistes Français

Referencia electrónica

Mercé Pujol Berché, «Lenguas cooficiales en una Cataluña multilingüe y lengua habitual en los usos particulares», HispanismeS [En línea], 16 | 2020, Publicado el 01 diciembre 2020, consultado el 31 agosto 2021. URL: http://journals.openedition.org/hispanismes/799 ; DOI: https://doi.org/10.4000/ hispanismes.799

Este documento fue generado automáticamente el 31 agosto 2021.

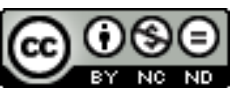

Les contenus de cette revue sont mis à disposition selon les termes de la Licence Creative Commons Attribution - Pas d'Utilisation Commerciale - Pas de Modification 4.0 International. 


\title{
Lenguas cooficiales en una Cataluña multilingüe y lengua habitual en los usos particulares
}

\author{
Les langues co-officielles dans une Catalogne multilingue et la langue usuelle \\ dans l'usage privé \\ Co-official languages in a multilingual Catalonia and the language customary in \\ private usage
}

Mercé Pujol Berché

\section{Introducción}

Han transcurrido más de 40 años desde que en 1978 España se convirtió en una democracia. El artículo 3 de la Constitución otorgó a las llamadas lenguas propias catalán, gallego y vasco- el estatuto de lengua cooficial en sus respectivas comunidades autónomas. Durante esos más de cuarenta años, la sociedad española (la que reside en España) ha cambiado profundamente en muchos aspectos, en especial, en lo demolingüístico. Comunidades que en esa época presentaban un bilingüismo histórico, como Cataluña, se han convertido en sociedades multilingües debido a la globalización, al movimiento rápido, frecuente y numeroso de personas que «viajan y se asientan» con sus respectivas lenguas de origen. Cataluña ha sido una sociedad receptora de emigración, primero regional (del campo a la ciudad), luego geográficamente más lejana (sobre todo de la región de Murcia debido a la industrialización más temprana en Cataluña que en el resto de España salvo en el País Vasco), después de emigración interna (población castellanohablante que llegó de forma masiva a partir de los años sesenta del siglo pasado), y posteriormente de emigración tanto comunitaria como extracomunitaria (población con gran diversidad lingüística que llegó también de forma masiva a partir de los años noventa del siglo pasado). 
2 La emigración interna -castellanohablante- en plena dictadura franquista, en la que el uso del catalán estaba prohibido, puso en contacto constante y permanente ambas lenguas, el castellano y el catalán. Las condiciones de uso de la lengua autóctona estaban muy restringidas, pero a pesar de ello, la lengua pudo mantenerse al menos en una gran parte de la población. La emigración posterior, también masiva, procedente de todo el mundo, puso de nuevo al catalán en contacto, esta vez, con muchas lenguas. Estos dos aluviones de población no catalanohablante, el largo periodo franquista de represión de las otras lenguas que no fueran el castellano y la persistencia de la negación de una España diversa han conducido a la lengua catalana, que se considera una lengua media ${ }^{1}$, a una situación de lengua minorizada en su propio territorio. Si a estos tres aspectos le añadimos otros tres elementos con relación al castellano, como son la supremacía y la protección jurídica de que goza dicha lengua en el Estado español, su peso demográfico y su categoría de lengua internacional, nos encontramos en el caso del catalán ante una lengua que, a pesar de la normalización lingüística que se lleva a cabo en Cataluña, está en una situación precaria de uso. La emigración que permite el contacto de lenguas y de culturas también ocasiona cambios demolingüísticos en la sociedad. Así se calcula que hay más de 300 lenguas en Cataluña, según datos del GELA (Grup d'Estudis de Llengües Amenaçades)², con una población extranjera que asciende a $1.082 .099^{3}$, lo que representa el 14,28 \% de la población.

3 Nuestro objetivo es exponer, a partir de los datos obtenidos en la última encuesta sobre los usos lingüísticos de la población (EULP 2018) ${ }^{4}$, cómo se reparte en el territorio de Cataluña la población que tiene como lengua habitual el catalán, qué lenguas son consideradas habituales en los hogares catalanes (los hogares que viven en Cataluña), cuáles son los ámbitos de uso de las lenguas cooficiales y cómo inciden estas en la elección de la lengua de identificación por parte de los marroquíes ya que son los extranjeros más numerosos en dicha comunidad autónoma. Nuestra hipótesis es que el uso de la lengua propia como lengua habitual se mantiene. Recordaremos en la primera parte el marco constitucional y estatutario con los artículos referentes a las lenguas; en la segunda, expondremos los datos relativos a la población extranjera; en la tercera parte, pondremos a prueba nuestra hipótesis con los datos que nos proporciona la Encuesta sobre los Usos Lingüísticos de la Población e intentaremos, a partir de ellos, evocar los desafíos a los que se enfrenta Cataluña con una sociedad civil multilingüe y con dos lenguas cooficiales de las cuales la lengua propia se encuentra minorizada ante la lengua del Estado, mayoritaria, compartida por una parte de la población emigrante (hispano-americana) e internacional.

\section{Marco constitucional y estatutario: la España de las autonomías y las lenguas cooficiales}

4 Para contextualizar los datos sociolingüísticos expuestos en el presente artículo, y evitar cualquier interpretación errónea, es necesario recordar que el marco constitucional da cabida a las otras lenguas de España distintas a la castellana. Mencionaremos rápidamente tres puntos: el primero, el artículo 3 de la Constitución española de 1978; el segundo, los artículos de la Constitución que dieron paso a los estatutos de las comunidades autónomas; el tercero y último, el artículo 6 del estatuto de Cataluña de 2006.

El artículo 3 de la Constitución española de 1978 reza de la siguiente forma. 
3.1.: El castellano es la lengua oficial del Estado [...]. 3.2.: Las otras lenguas de España son igualmente oficiales en sus respetivas Comunidades autónomas según sus estatutos. 3.3.: La riqueza de las diferentes modalidades lingüísticas de España representa un patrimonio cultural que será objeto de una protección y de un respeto particulares ${ }^{5}$.

Dicho artículo se redacta teniendo en cuenta el artículo 8 del anteproyecto de constitución de la monarquía española, que rezaba de la siguiente manera: «El idioma oficial de la nación española es el castellano», así como en el artículo 4 de la Constitución republicana del 9 de diciembre de 1931: Art. 4 del título preliminar:

El castellano es el idioma oficial de la República. Todo español tiene obligación de saberlo y derecho de usarlo, sin perjuicio de los derechos que las leyes del Estado reconozcan a las lenguas de las provincias o regiones. Salvo lo que se disponga en leyes especiales, a nadie se le podrá exigir el conocimiento ni el uso de ninguna lengua regional ${ }^{6}$.

7 La República ofrecía una coexistencia pacífica, capaz de admitir el pluralismo territorial y el concepto de nación tenía, como lo menciona Molas ${ }^{7}$, contenidos más políticos y menos emocionales que en la actualidad. El artículo 50 de dicha Constitución rezaba de la siguiente forma:

Las regiones autónomas podrán organizar la enseñanza en sus lenguas respectivas, de acuerdo con las facultades que se conceden en sus Estatutos. Es obligatorio el uso de la lengua castellana y ésta se usará también como instrumento de enseñanza en todos los Centros de instrucción primaria y secundaria de las regiones autónomas.

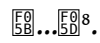

8 De este modo, la Generalitat de Cataluña organizó la enseñanza del y en catalán para los maestros 9 .

9 Algunos autores ${ }^{10}$ han calificado a la España de las autonomías como un «Federalismo sin Estado federal», otros ${ }^{11}$ como una Federación de España caracterizada por una competencia etnoterritorial múltiple. Lo llamado por los políticos de forma un tanto popular el «café para todos» se refería a la uniformización de trato de todas las comunidades autónomas sin distinción entre las denominadas históricas y las otras. En cuanto a las otras lenguas (y diferentes modalidades lingüísticas), la doble oficialidad es una cuestión jurídica en materia lingüística. Dicha doble oficialidad se rige por el principio de territorialidad, es decir que la lengua cooficial es oficial en su territorio, en su comunidad autónoma, mientras que el castellano, que es la lengua oficial en todo el Estado, es la lengua que debe utilizarse en las relaciones con el Estado español, sus autoridades, así como con otras regiones autónomas. La designación de las otras lenguas de España como lengua propia se refiere al concepto de propiedad y por lo tanto de singularidad. La lengua propia tiene tres funciones: la primera la de identificación, es decir la de su uso en las instituciones de la comunidad autónoma; la segunda la de resolución, es decir la lengua preferente para resolver conflictos y, la tercera, la normalizadora, es decir la de tener un trato de favor hacia la misma.

Sigue existiendo, a pesar de que se considera que España disfruta de una democracia consolidada, la denominada violencia simbólica ${ }^{12}$, puesto que las relaciones de poder que ejerce el grupo mayoritario (de habla castellana) sobre el grupo minoritario (de habla catalana) tienen como finalidad la obtención de mayor espacio social ${ }^{13}$. Se construye así una serie de normas y valores que favorecen a dicho grupo dominante en detrimento del grupo minoritario. Además, los diferentes partidos políticos tienen visiones distintas de España, por lo tanto de la nación, y las tensiones estructurales con 
relación a las lenguas cooficiales siguen sin resolverse ${ }^{14}$, lo que conlleva que frente a una política centralizada, homogénea y unitaria del Estado-nación con sus respectivas ideologías monoglósicas, como lo expone Moreno Cabrera ${ }^{15}$ en estos términos: la «situación de dominio absoluto del español sobre otras lenguas», surjan movimientos independentistas de ruptura, como ocurre en Cataluña.

Recordemos también, para disipar cualquier interpretación errónea, que las normas de las comunidades autónomas tienen la misma jerarquía que las del Estado, pero sin interferencias, ya que las comunidades autónomas solo pueden promulgar normas según sus competencias. En caso de conflicto, le corresponde al Tribunal Constitucional intervenir. Cataluña accedió por la llamada vía rápida (artículo 151 de la Constitución) a la autonomía, su primer estatuto vio la luz en el año 1979 y se reformó ${ }^{16}$ en el año 2006. Recordemos que accedieron también a la autonomía por la vía rápida, consideradas asimismo como comunidades históricas, el País Vasco, Galicia y Andalucía, el primero vio su primer estatuto en el año 1979, como Cataluña, mientras que las dos últimas lo obtuvieron dos años más tarde, en 1981. En las otras dos comunidades autónomas en las que el catalán (valenciano) es también lengua cooficial, los respectivos estatutos se obtuvieron en 1982 (Comunidad valenciana por la vía media, artículo 150.2) ${ }^{17}$ y en 1983 (Baleares por la vía lenta, artículo 143) ${ }^{18}$.

12 Evoquemos también, sobre cuestiones jurídicas, el artículo 6 del Estatuto de autonomía de $2006^{19}$ que legitima más la lengua catalana, pero que el fallo del Tribunal constitucional de junio de $2010^{20}$ consideró, junto con otros artículos, anticonstitucional. Una de las diferencias entre el estatuto de 1979 y el de 2006 con relación a la lengua propia es justamente el hecho de que los ciudadanos de Cataluña deben conocer ambas lenguas.

Art. 6.1.: La lengua propia de Cataluña es el catalán. Como tal, el catalán es la lengua de uso normal y preferente ${ }^{21}$ en las Administraciones públicas y en los medios de comunicación públicos de Cataluña, es también la lengua normalmente utilizada como vehicular y de aprendizaje ${ }^{22}$ en la enseñanza.

Art. 6.2: El catalán es la lengua oficial de Cataluña. También lo es el castellano, que es la lengua oficial del Estado español. Todas las personas tienen derecho a utilizar las dos lenguas oficiales y los ciudadanos de Cataluña el derecho y el deber de conocerlas. Los poderes públicos de Cataluña deben establecer las medidas necesarias para facilitar el ejercicio de estos derechos y el cumplimiento de este deber. De acuerdo con lo dispuesto en el artículo 32, no puede haber discriminación por el uso de una u otra lengua ${ }^{23}$.

Por último, mencionemos que la normalización lingüística consiste en reorganizar las funciones lingüísticas de la sociedad en el ámbito estrictamente lingüístico y sociopolítico para evitar la sustitución lingüística. La Generalitat de Cataluña trabaja desde 1979 a favor de una política lingüística para la lengua catalana (Ley de normalización lingüística, Ley 7/1983 $3^{24}$ ): primero de recuperación de la lengua, luego de planificación con el Plan general de normalización lingüística (1980-1995), posteriormente de mantenimiento con la aprobación de la nueva ley de política lingüística de 1998 (Ley 1/1998 de 7 de enero) con la creación del Consorcio para la Normalización Lingüística (CPNL) y a partir de los años 2000 de sostenibilidad con el Plan de acogida y de integración de la nueva inmigración y la gestión de la diversidad ${ }^{25}$. La lengua se instituye, en el caso catalán, como una herramienta de cohesión social, de inclusión y de identidad como hemos puesto de relieve en algunos trabajos ${ }^{26}$. Cabe decir que se ha llevado a cabo la política lingüística mediante el modelo llamado Top down, es decir de manera macro-lingüística interviniendo en el corpus (gramáticas, diccionarios, 
etc.), en el estatus (cooficialidad) y en los medios de comunicación (aunque en este apartado queda mucho por hacer ${ }^{27}$ ). Está pendiente de llevar a cabo en la normalización, siguiendo un modelo Down top, lo micro-lingüístico, todo lo relacionado con los individuos como hablantes (actitudes, uso que hacen de las lenguas e incluso emociones). Es en los individuos y en el uso que hacen de las lenguas en lo que nos interesaremos en los siguientes apartados.

\section{Población extranjera en Cataluña}

La población residente en Cataluña se eleva a $7.600 .267^{28}$ personas con una población extranjera de 1.082 .099 , lo que representa el $14,28 \%$ de la población total, con un aumento del 3,9 \% con relación a las cifras de 2017. Los datos extraídos del Padrón municipal de 2019, es decir 1 año después, indican que la población extranjera ha aumentado, situándola en un 15,1 \% de la población total. Lo que interesa poner en evidencia de ese casi $15 \%$ de población extranjera no es la nacionalidad, sino las lenguas. La población es muy heterogénea tanto desde el punto de vista de su procedencia, como de sus culturas y de sus lenguas de origen. Se calcula que hay más de 300 lenguas presentes en Cataluña ${ }^{29}$. En los cuadros siguientes (número 1 y número 2), se puede observar la distribución de dicha población extranjera, primero por continentes de procedencia (cuadro número 1) y posteriormente (cuadro número 2) según su procedencia por países deteniéndonos solo en aquellos con mayor número de ciudadanos.

Se observa en el cuadro número 1 que la población extranjera procede de todo el planeta como consecuencia de la mundialización. La población procedente de la Unión europea es la más numerosa, probablemente como consecuencia de la construcción europea, y representa casi la tercera parte de la población total extranjera, mientras que un poco más de la cuarta parte $(26,67 \%)$ procede del continente africano. Los procedentes del continente americano (sin distinción de país o de lenguas) representan la mitad $(50,20 \%)$ de la población extranjera.

Cuadro número 1: Población extranjera según su procedencia

\begin{tabular}{|l|l|}
\hline Población extranjera & Porcentajes \\
\hline Unión europea & $32,85 \%$ \\
\hline África & $26,67 \%$ \\
\hline América del Norte & $25,4 \%$ \\
\hline América del Sur & $17,75 \%$ \\
\hline Asia & $14,75 \%$ \\
\hline América central & $4,57 \%$ \\
\hline Caribe & $2,48 \%$ \\
\hline Oceanía & $0,08 \%$ \\
\hline
\end{tabular}


\begin{tabular}{|l|l}
\hline Apátridas & $0,01 \%$
\end{tabular}

Fuente: elaboración propia a partir de www.idescat.cat

Veamos ahora cuáles son los países de procedencia fijándonos solo en aquellos que tienen una mayor presencia numérica. Se puede apreciar (cuadro número 2) que las personas procedentes de Marruecos son mayoritarias, con una población que representa casi la quinta parte de los extranjeros (19,52 \%). En efecto, los marroquíes son, desde hace bastantes años, el grupo emigrante más numeroso en Cataluña ${ }^{30}$. Le sigue, pero a distancia, la emigración procedente de Rumanía $(8,24 \%)$ y de China $(5,49$ $\%)$. En cuanto a los procedentes de la Unión europea, cabe mencionar a los italianos $(5,16 \%)$ y a los franceses, con un pequeño porcentaje $(3,07 \%)$. Con relación a los ciudadanos de nacionalidad italiana, podríamos inferir que algunos de ellos proceden de Argentina y que son descendientes de antiguos emigrantes italianos y que, por lo tanto, son hispanohablantes. Con relación a los ciudadanos de nacionalidad francesa, debemos tener en cuenta que su presencia se debe tanto a la instalación de un número importante de empresas francesas en la región (el 18,5 \% de las empresas francesas están ubicadas en Cataluña) ${ }^{31}$, como a la cercanía (y frontera) entre Cataluña-España y Francia.

Cuadro número 2: Población extranjera por países

\begin{tabular}{|l|l|}
\hline Países & Porcentajes \\
\hline Marruecos & $19,52 \%$ \\
\hline Rumanía & $8,24 \%$ \\
\hline China & $5,49 \%$ \\
\hline Italia & $5,16 \%$ \\
\hline Pakistán & $4,17 \%$ \\
\hline Honduras & $3,12 \%$ \\
\hline Francia & $3,07 \%$ \\
\hline
\end{tabular}

Fuente: elaboración propia a partir de www.idescat.cat

Estos datos estadísticos nos permiten poner en evidencia, una vez más, la diversidad lingüística de los residentes en Cataluña, que sobrepasa en gran medida el bilingüismo histórico de dicha comunidad autónoma. Sobre el bilingüismo de Cataluña deberíamos mencionar que lo que se conoce del mismo es, como lo mencionan Bernat et alii ${ }^{32}$, parcial y fragmentario puesto que no hay estudios sobre ello. Lo que sí se puede apuntar es que los siglos XIX y XX son cruciales porque es cuando se produce la bilingüización del conjunto de la población catalana, que empieza sobre todo por parte de las élites urbanas y en situaciones formales. Sigue la bilingüalización con la Ley Moyano (1857) de escolarización obligatoria, aunque más del 50 \% de la población 
española era analfabeta, y posteriormente con la dictadura de Primo de Rivera, en la cual se prohíbe el catalán. Durante el periodo de la II República el catalán vuelve a recuperarse gracias al Decreto de Bilingüismo de 1931, pero otra dictadura (la del General Franco), prohíbe nuevamente el uso de esta lengua y la alfabetización masiva en castellano completa la bilingüización de la población. La llegada masiva de la inmigración interna de habla castellana a partir de los años cincuenta y sobre todo sesenta del siglo XX modifica profundamente los usos lingüísticos de la población, que va tendiendo hacia la convergencia lingüística en castellano.

\section{La encuesta sobre los usos lingüísticos de la población}

Como apunta Mari ${ }^{33}$, siguiendo lo propuesto por Corbeil ${ }^{34}$ a propósito de la planificación lingüística de Quebec, en la cual se inspiran bastantes aspectos de la planificación lingüística llevada a cabo en Cataluña, hay que diferenciar entre los usos institucionalizados o institucionales que, según este mismo autor, podrían designarse como profesionales, y los usos individualizados o individuales, que podrían designarse como usos particulares. Los que nos interesan en el presente artículo son, en especial, estos últimos, es decir los usos individuales, aunque, como indica Bastardas ${ }^{35}$, la comunicación institucionalizada y la comunicación individualizada no siempre se pueden diferenciar nítidamente puesto que en las sociedades bilingües o multilingües el uso social de las lenguas es de una gran complejidad. En los usos particulares, los hablantes se expresan de forma individual, su identidad personal es activa ${ }^{36}$ e incluso en un marco institucional, los hablantes actúan según sus propios criterios de comportamiento, mientras que en los usos profesionales los hablantes tienen una función predeterminada y se expresan como miembros de un colectivo; la identidad personal está relativamente desactivada. La planificación lingüística catalana se ha ocupado de ambos, aunque según el periodo y el momento, uno ha prevalecido sobre el otro, provocando un efecto de péndulo como también lo indica Maríi ${ }^{37}$. Siguiendo esta misma terminología, Fabà Prat ${ }^{38}$ ha examinado la evolución de los usos profesionales en Cataluña entre 1997 y 2008. Recogeremos un poco más abajo algunos datos de este trabajo sobre los usos con los vecinos, que no vamos a considerar como profesionales, sino como individuales y particulares, puesto que nos parece una designación más adecuada.

\subsection{La encuesta}

19 La encuesta sobre los usos lingüísticos de la población ${ }^{39}$ se realiza de forma quinquenal y la lleva a cabo la Dirección general de Política Lingüística del Departamento de Cultura de la Generalitat de Cataluña ${ }^{40}$. Este tipo de encuesta se realiza desde el año $2003^{41}$, por lo que se tienen datos de 2003, 2008, 2013 y 2018, lo que permite observar las evoluciones de los factores motivo de estudio. En la última encuesta, la de 2018, de la cual nos vamos a ocupar, el número de personas encuestadas de manera multicanal (mediante internet, encuesta telefónica o encuesta presencial) fue de $9.000^{42}$ de muestra teórica y de 8.780 individuos de muestra real, con muestreo estratificado y efectuado aleatoriamente en dos etapas, primero por municipios o sección de residencia y luego por individuos (sexo, grupo de edad y lugar de nacimiento), siguiendo la metodología 
de las investigaciones sociolingüísticas. La edad de los encuestados es de 15 años o más. Los datos fueron actualizados el 8 de julio de 2019. La finalidad de dicha encuesta es la de observar «la estimación de los usos lingüísticos en las relaciones interpersonales en Cataluña en diversos ámbitos de uso» ${ }^{43}$.

Nos hemos interesado por dicha encuesta porque nos da una fotografía sobre el uso de las lenguas en Cataluña (lo que dicen los hablantes a propósito del uso que hacen de sus lenguas) y nos permite compararlo de manera diacrónica con los datos obtenidos en encuestas anteriores. Institucionalmente, a la Dirección General de Política Lingüística le sirve para evaluar el conocimiento de las dos lenguas cooficiales $\mathrm{y}$, algo de suma importancia, evaluar el llamado uso social del catalán. La Dirección General de Política Lingüística mediante la Secretaría de Política Lingüística pone en marcha de manera regular campañas de sensibilización y de dinamización para fomentar el uso interpersonal de la lengua catalana ${ }^{44}$.

Entre los factores que se tienen en cuenta están las lenguas de la población en cuanto lengua inicial, de identificación y habitual, así como las actitudes lingüísticas de la población y opiniones sobre el uso del catalán. De este modo, dicha dirección general puede observar: a) si la política lingüística que lleva a cabo produce los frutos esperados; b) las fluctuaciones en el uso y sus ámbitos tanto en la esfera pública como en los ámbitos privado y familiar. Las políticas lingüísticas se realizan, como decíamos unas líneas más arriba, en pro de las lenguas minoritarias o minorizadas para paliar la pérdida de hablantes y para reorganizar las funciones que se le atribuyen. El catalán es una lengua minoritaria frente el castellano, aunque se considera que es una lengua media porque su peso demográfico se sitúa entre los 500.000 hablantes y los 25.000 .000 de hablantes ${ }^{45}$.

\subsection{Lengua habitual}

22 Empecemos por observar los datos relativos a la lengua habitual. En la encuesta, se considera que la lengua habitual es aquella que la persona entrevistada utiliza más frecuentemente, que puede coincidir o no con la lengua inicial o de identificación. En otras palabras, la lengua habitual responde a las preguntas sociolingüísticas de tipo "a quién habla, de qué, en qué situación, etc.». El primer dato importante arrojado por la encuesta de 2018 es que el 13 \% de la población encuestada no tiene como lengua habitual ninguna de las dos lenguas cooficiales, lo que representa un aumento del 3,7 \% con relación a los datos de la encuesta anterior, realizada en 2013. Esto corrobora el hecho de que la sociedad catalana (la que vive y reside en Cataluña ${ }^{46}$ ) está dejando de presentar, de forma exclusiva, su bilingüismo, ya histórico. Catalunya es una sociedad multilingüe en la que hay personas bilingües, monolingües y políglotas; con ello queremos decir que la "población civil" es, en cuanto a lenguas, heterogénea.

El segundo dato importante es que un poco más del tercio de la población $(36,1 \%)$ declara tener como lengua habitual el catalán, lo que corrobora de nuevo que la llamada lengua propia sigue estando minorizada, puesto que un poco más del tercio de la población dice tener esta lengua como hábito de utilización. El catalán como lengua inicial, por lo tanto como primera lengua, retrocede: este porcentaje llegaba al 31,3\% en $2013^{47}$, al 37,6 \% en 2008 e incluso al 47 \% en 1997, según datos extraídos estos dos últimos de los análisis realizados por Torras-Pla ${ }^{48}$. Dicho de otra forma, en veinticinco años, el catalán como lengua inicial ha retrocedido 16 puntos. Este descenso en cuanto 
al catalán como lengua inicial contradice la posición de los firmantes del Manifiesto por una lengua común publicado en junio de 2008 en El País ${ }^{49}$ sobre la pérdida del uso del castellano y su sustitución por el catalán ${ }^{50}$. El gran retroceso entre 1997 y 2008 se debe, en parte, a la llegada masiva de la nueva inmigración, cuyo punto de inflexión se sitúa a finales de la década de los años noventa del siglo pasado. Sin embargo, el porcentaje de personas que tienen el catalán como lengua habitual se mantiene puesto que en 2013 este porcentaje era de $36,4 \%^{51}$ y en 2018 es de $36,1 \%$. Nos parece un dato interesante puesto que, a pesar de su descenso como lengua inicial, es decir de aquellos que dicen tenerla como primera lengua, se mantiene como lengua habitual, es decir de aquellos que no la tienen como inicial, pero la usan de forma cotidiana.

El porcentaje del $36,1 \%$ es la media que se obtiene teniendo en cuenta los resultados de los ocho territorios que componen el plan territorial catalán. Como se puede observar en el gráfico número 1, los porcentajes de uso del catalán como lengua habitual se sitúan en un continuum que va desde el 27,5 \% en la región metropolitana (Barcelona, las comarcas colindantes y cercanas que corresponden a su zona de su influencia) hasta la zona sur de Cataluña (Las Tierras del Ebro) fronteriza con la Comunidad valenciana, cuyo porcentaje se eleva al $72,2 \%$. Como era de esperar la ciudad condal y su amplia área de influencia, que presenta probablemente la mayor diversidad lingüística (aunque no siempre), es aquella en la que la lengua propia es lengua habitual en menos de un tercio de la población $(27,5 \%$ ). Las comarcas más alejadas de la capital catalana son aquellas cuyo porcentaje es más elevado (territorios de Ponente y Alto Pirineo y Valle de Arán con porcentajes respectivamente del 57 \% y 58,8 \%). Las comarcas denominadas Centrales con un 59,6 \% se sitúan geográficamente más cerca de Barcelona que las que acabamos de mencionar, con lo cual lo que aquí influye no es la distancia geográfica y objetiva con la capital, sino probablemente el hecho de que son comarcas y pueblos con fuerte tradición catalanista e incluso independentista, como es el caso de la comarca de Osona con su capital Vic, en cuya plaza mayor se pueden observar las fotografías de los políticos encarcelados a raíz del referéndum del 1 de octubre de 2017.

Otro dato interesante es que hay un salto cuantitativo importante (más de 10 puntos) entre el porcentaje observado en el territorio metropolitano (menos del tercio de la población, $27,5 \%$ y el siguiente con menor porcentaje de personas que tienen el catalán como lengua habitual. Esto puede interpretarse considerando al menos tres parámetros: a) más del $42,7 \%$ de la población reside en esa área ${ }^{52}$; b) la propia Barcelona como ciudad cosmopolita que es; c) la actividad económica que en ella se desarrolla que representa más del $50 \%(50,9 \%)$ del PIB de la comunidad autónoma ${ }^{53}$. Estos aspectos tanto demográficos como económicos atraen a una población diversa y heterogénea que se dirige hacia las grandes urbes y su zona metropolitana llevando consigo, por su origen, una gran cantidad de lenguas diferentes. 


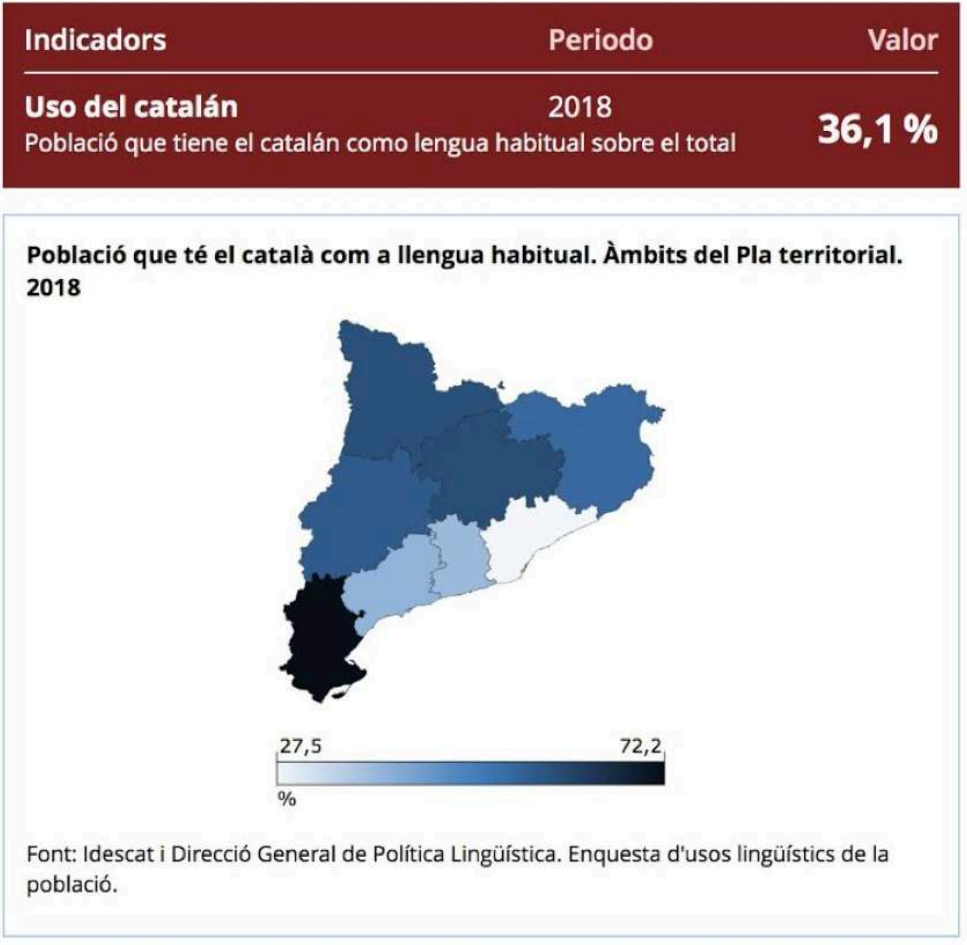

Fuente: Idescat y Direcció General de Política Lingüística, Enquesta d'usos lingüístics de la població.

El cuadro número 3 expone porcentualmente la población que declara tener el catalán como lengua habitual según el plan territorial. Las comarcas que componen el territorio de Centrales son rurales y tienen, como el resto de Cataluña, una población extranjera ya asentada (12,7 \% de la población, según datos de 2019). Las comarcas de las Tierras del Ebro tienen un mayor porcentaje de población extranjera que las anteriores, llegando al 16,1 \%, con lo cual la presencia de población extranjera no es la única causa de disminución del número de personas que tienen el catalán como lengua habitual. Como se ha mencionado con anterioridad, la emigración provoca cambios demolingüísticos, pero no hay causalidad entre este aspecto y la disminución del porcentaje de personas que declara tener el catalán como lengua habitual. Este puede ser uno de los factores, pero no el único. Si ahora dentro del ámbito metropolitano, tomamos la población extranjera y nos concentramos en la comarca del Barcelonès que tiene una población extranjera de 19,2 \% y la ciudad de Barcelona, con una población extranjera de 19,6 \% (3 de cada 10 extranjeros viven en la ciudad condal), podemos interpretar estos datos mencionando que no es la presencia de población extranjera el factor más importante, sino la ruralidad o la urbanidad. Zona rural y poca densidad de población son factores favorables a que los individuos tengan (mantengan o incorporen) como lengua habitual la lengua catalana. Otro factor importante en las Tierras del Ebro es la transmisión lingüística intergeneracional, como se puso de manifiesto en la encuesta realizada en 2013.

En el estudio de los usos de las lenguas en contextos multilingües, que, por definición, son sociedades lingüísticamente complejas, hay que buscar otras dinámicas para explicar los comportamientos lingüísticos. No nos podemos limitar a buscar un factor y a usarlo como causa de la disminución de uso. Por eso nos parecer interesante lo que 
llevamos mencionando desde hace varios años ${ }^{54}$, el multilingüismo presente en la sociedad catalana es un factor importante en el mantenimiento de la lengua minoritaria puesto que sabemos que una de las primeras etapas en la pérdida de las lenguas es la bilingüalización de la población. En efecto, cuando la población es únicamente bilingüe, una de las lenguas (normalmente la minoritaria y dominada) va desapareciendo poco a poco, puesto que sus funciones se ven reducidas cada vez más. En las sociedades multilingües todas las lenguas van siendo utilizadas. Otro factor importante es obviamente la transmisión intergeneracional, tanto en familias monolingües, como bilingües y multilingües. Pero para ello, hay que tomar la decisión de transmitir las lenguas y, sobre todo, de cumplir («a raja tabla») dicha decisión.

Cuadro número 3: Lengua habitual catalana de la población según el territorio de residencia

\begin{tabular}{|l|l|}
\hline Plan territorial & Porcentajes \\
\hline Ámbito metropolitano & $27,5 \%$ \\
\hline Penedés & $38,9 \%$ \\
\hline Campo de Tarragona & $40,4 \%$ \\
\hline Comarcas gerundenses & $54,1 \%$ \\
\hline Ponente & $57 \%$ \\
\hline Alto Pirineo y Arán & $58,8 \%$ \\
\hline Centrales & $59,6 \%$ \\
\hline Tierras del Ebro & $72,2 \%$ \\
\hline
\end{tabular}

Fuente: elaboración propia a partir de www.idescat.cat

\subsection{Uso de las lenguas según el ámbito de uso: en el hogar}

Veamos ahora los usos lingüísticos de la población en función del ámbito de uso. Se denomina uso lingüístico «aquello que el individuo comunica activamente hablando o escribiendo en una lengua y aquello que el individuo recibe pasivamente entendiendo o leyendo una lengua» ${ }^{55}$. Observemos qué ocurre en el hogar (cuadro número 4), definido como «las personas o el conjunto de personas que ocupan en común un alojamiento familiar principal o una parte y que comparten un presupuesto común» ${ }^{56}$. El 40,5 \% de los encuestados declara que la lengua habitual en el hogar es solo el castellano. Si a este porcentaje le añadimos el porcentaje concerniente al de los hogares en los que se declara hablar más en castellano, se llega a que la mitad de la población encuestada $(51,1 \%)$ tiene como lengua habitual el castellano. Un poco más del tercio $(35,8 \%)$ declara que su lengua habitual es el catalán o más el catalán que el castellano. Estos datos reflejan que el castellano es ampliamente mayoritario en los usos individuales y más concretamente en el ámbito más privado como es el hogareño. Los datos de la encuesta no nos brindan las razones de esto, aunque sin embargo podemos avanzar 
algunas interpretaciones. La emigración interna, ampliamente asentada y con presencia de varias generaciones, sigue usando mayoritariamente su lengua de origen y sigue transmitiéndola a las generaciones futuras.

Cuadro número 4: Lengua habitual en el hogar

\begin{tabular}{|l|l|l|l|l|l|l|}
\hline & Solo catalán & Más catalán & Catalán y castellano & Más castellano & Solo castellano & Otras \\
\hline 2018 & $29,8 \%$ & $6 \%$ & $8,2 \%$ & $10,6 \%$ & $40,5 \%$ & $4,9 \%$ \\
\hline $2008^{57}$ & $31,6 \%$ & $3,6 \%$ & $8,3 \%$ & $6 \%$ & $42,5 \%$ & $8 \%$ \\
\hline
\end{tabular}

Fuente: Elaboración propia a partir de www.indescat.cat

Si comparamos los datos de forma diacrónica (encuestas de 2018 y de 2008), podemos observar un descenso de 2 puntos en aquellos que tienen únicamente el catalán como lengua habitual, mientras que observamos ese mismo porcentaje pero ascendente en aquellos en los que la lengua habitual es la castellana. El porcentaje de los que dicen tener ambas lenguas se mantiene. Hay un aumento de casi dos puntos en los encuestados que dicen que su lengua habitual es la castellana o más la castellana ( 48,5 $\%$ en 2008 y 50,1 \% en 2018). Es interesante observar el descenso en el porcentaje de personas que dicen tener como lengua habitual otras lenguas en el hogar ( $8 \%$ en $2008 \mathrm{y}$ $4,9 \%$ en 2018). Este descenso puede explicarse por el hecho de que la población extranjera en Cataluña también ha descendido en dicho período (la población extranjera en 2008 representaba el $15,75 \%$ de los residentes en Cataluña ${ }^{58}$, mientras que en 2018 representa el 14,24\%). Este descenso también puede explicarse por el hecho de que parte de la población extranjera no hispanohablante ha adoptado en el hogar alguna de las dos lenguas cooficiales. Cabe recordar que la población ecuatoriana y boliviana que representaban juntas el 8,7 \% de la población extranjera en Cataluña en $2008^{59}$, en 2018 representan solamente el 4,34\% de la misma. Estos dos grupos, como otros, son menos numerosos en 2018 debido entre otros factores al hecho de la crisis económica de España a partir del año 2008 y al regreso de una parte de dicha población hacia sus lugares de origen. En efecto, las políticas de retorno al país y del Buen Vivir llevadas a cabo por el presidente Correa en Ecuador llevaron a invertir el proceso de los ecuatorianos en España y convirtieron a ese país de emigrantes en país de recepción de inmigrantes como así lo sugieren, entre otros, los estudios de Antón Hurtado y Mattarazo ${ }^{60}$.

30 Sería interesante conocer qué declara como lengua habitual en el hogar la población marroquí puesto que era mayoritaria en 2008 y sigue siéndolo en 2018 (12,7 \% de la población en $2008^{61}$ y 19,52 \% en 2018). La población marroquí instalada en Cataluña también es heterogénea en cuanto a lenguas puesto que pueden tener como primera lengua el árabe dialectal con diferentes variantes, el amazigh con presencia de varios dialectos bereberes septentrionales y en algunos casos el francés.

\section{3. Ámbito de uso en la vecindad}

31 Observemos ahora qué ocurre con la lengua habitual de uso con los vecinos. El uso solo de una de las lenguas cooficiales sigue desciendo en un periodo de 10 años (cuadro 
número 5), pasando de $40,2 \%$ a $37 \%$ para el castellano (descenso de 3 puntos) y de 22,7 $\%$ a 16,7 \% para el catalán (descenso de 6 puntos). El uso del catalán como lengua habitual con los vecinos disminuye constantemente puesto que en 1997 el porcentaje llegaba al 38,9 \% ${ }^{62}$. Aumenta en 8 puntos el porcentaje de encuestados que declara usar ambas lenguas como habituales (pasando del 34,6\% en 2008 al 42,3\% en 2018), con lo que podemos decir que en los usos individuales públicos y cercanos, como es el caso de la vecindad, los encuestados dicen utilizar ambas lenguas. El castellano sigue siendo la lengua habitual más usada en el ámbito vecinal. Además, en dicho espacio público aparecen otras lenguas diferentes a las dos cooficiales (porcentaje del $4 \%$ ). El multilingüismo aparece, como mencionábamos al principio de este artículo, como consecuencia de la emigración y de la globalización, por lo tanto, en las relaciones interpersonales en el espacio público cercano se usan otras lenguas que no son ni el catalán ni el castellano. En diez años, el multilingüismo aumenta puesto que se pasa del $2,5 \%$ en 2008 al $4 \%$ en 2018. La población catalana, es decir la que reside en el Principado, está pasando de la bilingüización al multilingüismo, sobre todo por parte de la población marroquí.

Cuadro número 5: Lengua habitual con los vecinos

\begin{tabular}{|l|l|l|l|l|l|l|}
\hline & Solo catalán & Más catalán & Catalán y castellano & Más castellano & Solo castellano & Otras \\
\hline 2018 & $16,7 \%$ & $14,3 \%$ & $17,1 \%$ & $10,9 \%$ & $37 \%$ & $4 \%$ \\
\hline 2013 & $17,2 \%$ & $14,6 \%$ & $15,6 \%$ & $11,4 \%$ & $37,5 \%$ & $3,7 \%$ \\
\hline $2008^{63}$ & $22,7 \%$ & $9,5 \%$ & $16,5 \%$ & $8,6 \%$ & $40,2 \%$ & $2,5 \%$ \\
\hline
\end{tabular}

Fuente: Elaboración propia a partir de www.indescat.cat.

Volvamos al uso de las lenguas cooficiales: la lengua de uso para la tercera parte de la población encuestada es únicamente el castellano. Dicho de una forma más clara: el catalán no está sustituyendo al castellano. Teniendo en cuenta la población encuestada, dos datos nos parecen relevantes en cuanto al uso exclusivo del castellano: en los hogares y entre los vecinos su presencia alcanza casi el $40 \%(37,7 \%$ y $37 \%$ respectivamente), es decir en los usos individualizados. Estos datos pueden dar lugar a diferentes interpretaciones. Por una parte, aunque no sepamos con exactitud la composición lingüística de los hogares (familias mixtas, familias castellanohablantes, familias mixtas más allá del bilingüismo catalán-castellano), en una buena parte de ellos se ha optado por la lengua oficial del Estado, tal vez como lengua compartida o como lingua franca (familias mixtas «extranjeras»). En los ámbitos sociales y en particular en el espacio público cercano, como es el caso de la lengua empleada entre los vecinos, el castellano vuelve a ser la lengua privilegiada.

\subsection{La lengua de identificación}

33 Nos ha interesado conocer, por último, qué lengua es la lengua de identificación y la relación entre esta última y la lengua inicial y la lengua habitual ${ }^{64}$. La lengua de identificación es la «lengua que la persona entrevistada considera como suya y con la cual se identifica» ${ }^{65}$. En el caso del catalán, el $36,3 \%$ declara tener esa lengua como 
lengua de identificación, en el caso del castellano ese porcentaje llega al 46,6 \%. Los individuos que declaran identificarse con ambas lenguas presentan un porcentaje del $6,9 \%$. En el caso de la población que declara tener como lengua habitual el árabe, un porcentaje elevado $(71,9 \%)$ sigue identificándose con esta lengua, el $13,5 \%$ con otras lenguas (probablemente el bereber puesto que una parte importante de la emigración marroquí procede del Rif). Dentro de esta población, el 14,6 \% se identifica con el castellano y nadie se identifica con el catalán. En el caso del árabe, mientras que el 2,2\% de los individuos declara tener esa lengua como inicial, sólo el 1,8 \% declara tenerla como lengua de identificación, hay un pequeño descenso al considerar como suya la lengua árabe. La lengua predominante, es decir, el castellano, es la lengua que los individuos eligen para identificarse con ella, pero no la lengua propia. Lo mismo ocurre con los individuos que declaran tener como lengua habitual otras lenguas, puesto que el $18,5 \%$ de los mismos se identifica con el castellano. Se observa asimismo una disminución en todas las lenguas: por ejemplo, en el caso del bereber, el 0,5\% de los encuestados declara el bereber como lengua inicial, mientras que el 0,4 \% declara tener esa lengua como lengua de identificación. Algo distinto ocurre en el caso de una lengua internacional y de prestigio como es el inglés: el 0,4\% declara esa lengua como inicial mientras que el 0,5 \% la declara como lengua de identificación. Cuando las personas alóglotas, es decir aquellas que no tienen como lengua inicial ni el castellano, ni el catalán, eligen otra lengua diferente a la suya inicial, optan por la lengua mayoritaria, la que tiene la hegemonía, la lengua compartida por una parte de la población y la lengua internacional.

Hay que considerar estos datos con suma prudencia puesto que deberían tomarse en consideración otras variables como la lengua habitual de la pareja, el lugar de nacimiento de la población encuestada, la lengua habitual con los hijos, etc. Además, la prudencia también es de rigor debido al número muy reducido de población encuestada. Lo que tenemos que subrayar es que «la configuración demolingüística de Cataluña se encuentra sometida a una transformación continua, con tendencias

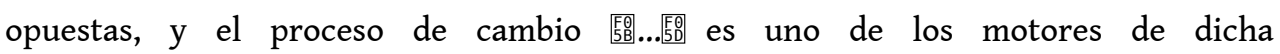
transformación ${ }^{66}$ ». La sociedad catalana es una sociedad compleja desde el punto de vista lingüístico y en constante cambio.

\section{Conclusiones}

A partir del marco constitucional que hemos recordado en la primera parte del presente artículo y de la normalización lingüística llevada a cabo por la Generalitat de Cataluña con respecto a la lengua catalana, hemos querido poner de manifiesto los cambios demolingüísticos importantes que se han producido en Cataluña en las últimas décadas. La sociedad de esta comunidad autónoma tomada en su conjunto ha dejado de ser bilingüe para pasar a ser multilingüe, puesto que la población extranjera que representa el 14,24 \% de la población tiene otras lenguas distintas a las dos lenguas cooficiales, siendo los marroquíes los emigrantes más numerosos (casi la quinta parte de dicha población extranjera). Teniendo en cuenta esta transformación, hemos puesto de manifiesto cómo se sitúa el catalán considerado como lengua habitual en los ocho territorios que componen el plan territorial de Cataluña. Lo primero que hemos puesto de manifiesto es que la lengua catalana considerada por los encuestados como habitual mantiene su porcentaje (36,4 \% en 2013 y $36,1 \%$ en 2018). Hemos podido observar, 
como era de esperar, que es en el ámbito metropolitano en donde el porcentaje es menor, mientras que el mayor se sitúa en las Tierras del Ebro, es decir en el sur de la comunidad autónoma, zona fronteriza con la comunidad valenciana y alejada, por lo tanto, de la zona de influencia de la capital catalana. La emigración conlleva cambios demolingüísticos importantes, pero no es el único parámetro que hay que tomar en consideración para explicar el porcentaje de personas que tienen el catalán como lengua habitual. De este modo, las Tierras del Ebro con un porcentaje del $16,1 \%$ de población extranjera tiene un porcentaje que llega al 72,2 \% de personas que tienen el catalán como lengua habitual. La poca densidad de población unida a la ruralidad son dos factores importantes para que las personas alóglotas adopten la lengua propia como habitual.

En cuanto al ámbito de uso, el castellano es la lengua que más se usa en el ámbito privado, como es el caso del hogar: el 40,5 \% de la población declara usar únicamente esta lengua en el hogar. Casi el $5 \%(4,9 \%)$ de la población declara usar otras lenguas. En el caso de las lenguas usadas con los vecinos, se observa un descenso tanto de aquellos que dicen usar solo el castellano como de aquellos que dicen usar solo el catalán, al comparar los datos de la encuesta de 2008 con la de 2018. Para el caso del castellano, el porcentaje disminuye de 3 puntos y en el caso del catalán el doble, es decir de 6 puntos. En los usos individuales, ya sea en el hogar, ya sea con los vecinos, los encuestados dicen usar mayoritariamente la lengua oficial del estado. En cuanto a la lengua de identificación, el porcentaje aumenta tanto en aquellos que tienen como lengua habitual el castellano, como en aquellos que tienen el catalán. Dicho de otra forma, aumenta el porcentaje en un punto cuando comparamos lengua de identificación (mayor porcentaje) y lengua habitual (menor porcentaje) (en el uso de cada una de las dos lenguas). Observamos también en la población marroquí que existe una tendencia por identificarse con el castellano y no con el catalán, aunque el número reducido de sujetos nos obliga a la máxima prudencia en la interpretación. El uso del catalán como lengua habitual también retrocedió, pero se mantiene más o menos estable desde 2008 y 2018. Si las autoridades que se ocupan de la planificación lingüística desean que ese porcentaje de uso del catalán como lengua habitual se mantenga y no retroceda, estas deben desarrollar acciones cuyo objetivo sea el de acercarse más a la población alóglota (emigrada) para que arropen (y usen) la lengua propia. Ese es uno de los grandes desafíos puesto que son los aspectos microlingüísticos, aquellos que hacen referencia a los individuos, los más difíciles de poner en marcha.

\section{BIBLIOGRAFÍA}

Fina ANTÓN HURTADO y Claudio MATTARAZO, «Invirtiendo la ruta del proceso de retorno de los ecuatorianos en España», Universitas, XIII (23) (2015), p. 35-64.

Josep Maria AYMÀ AUBEYZON, «Els usos interpersonals o privats a Catalunya. Balanç i perspectives de futur», Treballs de Sociolingüística Catalana, no 22 (2012), p. 59-72. 
Albert BASTARDAS, «Comunicacions institucionalitzades i comunicacions individualitzades: la complexitat de l'ús social de les llengües», Treballs de Sociolingüística Catalana, ㄲo 17 (2003), p. 315-322.

Albert BASTARDAS I BOADA, Emili BOIX-FUSTER y ROsa Mª TORRES GUERRINI, El català, llengua mitjana d'Europa. Multilingüisme, globalització i sostenibilitt lingüística. Barcelona, Octaedro, 2018.

Francesc BERNAT, Mireia GALINDO, y Carles de ROSSELLó, «Des de quan som bilingües els catalans», Apunts de sociolingüística i política lingüística, nº 7, CUSC (Centre de recerca en sociolingüística i comunicació), Barcelona, Universitat de Barcelona, 2019, p. 1-4.

Boletín Oficial del Estado. B.O.E., Legislación. Constitución, Madrid, Agencia estatal Boletín Oficial del Estado.

Boletín Oficial del Estado. B.O.E. nº 1578, Gaceta de Madrid, nº 344, de 10 de diciembre de 1931.

Pierre bouRdieu, Ce que parler veut dire. L'économie des échanges linguistiques, Paris, Fayard, 1982.

Chrystelle BURBAN, «Le buzz médiatique médiatique dans Manifiesto por la lengua común», Christian Lagarde (ed.), Le discours sur les 'langues d'Espagne' / El discurso sobre las 'lenguas de España', Perpignan, Presses Universitaires de Perpignan, 2009, p. 255-268.

Daniel CASALS MARTORELL, «Política i planificació lingüístiques durant la Segona República (1931-1939). Els cursos presencials no universitaris de català organitzats i promoguts per la Generalitat de Catalunya», Revista de Llengua i Dret, Journal of Language and Law, no 74 (2020), p. 58-74, [Disponible en línea], [⿰氵⿱一⿴⿻儿口一寸]URL: https://doi.org/10.2436/rld.i74.2020.3496>.

Jean-Claude CoRBEIL, L'aménagement linguistique du Québec, Montréal, Guérin, 1980.

DIRECCIÓ GENERAL DE POLÍTICA LINGÜÍSTICA (DGPL), Enquesta lingüística sobre l'ús oral del català entre la població de Catalunya major de 15 anys: Informe i resum, Barcelona, Generalitt de Catalunya, 1998. DIRECCIÓ GENERAL DE POLÍTICA LINGÜísTICA (DGPL), Accions, Barcelona, Generalitat de Catalunya, 2010. DIRECCIÓ GENERAL DE POLÍTICA LINGÜÍSTICA (DGPL), Enquesta d'usos lingüístics de la població 2008. Anàlisi. Volum I: Les llengües a Catalunya: coneixements, usos, transmissió $i$ actitutds lingüístics. Barcerlona, generalitat de Catalunya, 2011, [Disponible en línea], <URL: https://llengua.gencat.cat/ permalink/2e24ce66-5384-11e4-8f3f-000c29cdf219>

Albert FABÀ PRATS, «L'evolució dels usos professionals a Catalunya del 1997 al 2008», Treballs de Sociolingüística Catalana, nº 22 (2012), p. 41-58.

Albert FABÀ PRATS y Joaquim TORRES-PLA, «De la llengua inicial a la llengua d'identificació a Catalunya: qui adopta el català i qui se n'allunya», Treballs de Sociolingüística catalana, no 30 (2012), 213-232.

Alicia FERNÁNDEZ GARCÍA y Mathieu PETITHOMME, «Introduction. Du nationalisme d'État aux nationalismes espagnols, la réinvention de la « nation » espagnole depuis la transition démocratique», Alicia Fernández García y Mathieu Petithomme (dirs.), Les nationalismes dans l'Espagne contemporaine (1975-2011). Compétition politique et identités nationales, Paris, Armand Colin, 2012, p. 8-23.

GENERALITAT DE CATALUNYA, Perfil sociodemogràfic dels col-lectius més nombrosos a Catalunya. Xifres provisionals a 1 de gener de 2013, Barcelona, Departament de Benestar Social i Família, Direcció General per a la immigració, 2012. 
GENERALITAT DE CATALUNYA, Els usos lingüístics de la població a Catalunya. Resultats de l'enquesta d'usos lingüístics de la població 2018, Barcelona, Generalitat de Catalunya. Departament de cultura. Política Lingüística, 2021.

Josep GIFREU, «Procés de normalització del català en els mitjans de comunicació: notes sobre l'evolució de la recerca, 1980-2010», Treballs de Sociolingüística Catalana, nº 21 (2011), p. 73-82.

IDESCAT, EULP. Enquesta d'usos lingüístics de la població, Generalitat de Catalunya, <URL: https:// www.idescat.cat/pub/?id=eulp>.

IDESCAT, Evolució de la població total i estrangera. 2018, Barcelona, Genralitat de Catalunya, 2019, <URL: www.idescat.cat>.

Mª Carme JUNYENT, Pere COMELLAS, Montserrat CORTÈs-COLOMÉ, Mònica BARRIERAS, Eva MONRó y Mònica FIDALGO, La diversidad lingüística: una invitación a reconocerla, comprenderla e incorporarla, Barcelona, Horsori, 2014.

Georg KREMNITZ, «Les tensions actuelles entre la Catalogne et l'Espagne», Lengas [En ligne], $\mathrm{n}^{\mathrm{o}}$ 79 (2016), mis en ligne le 30 juin 2016, [Consultado el 14 noviembre de 2019], [50 [id URL: http:// journals.openedition.org/lengas/1040; DOI : 10.4000/lengas.1040[酋.

Christian LAGARDE (ed.), Le discours sur les « langues d'Espagne » / El Discurso sobre las « lenguas españolas » (1978-2008), Perpignan, Presses Universitaires de Perpignan, 2009.

Christian LAGARDE, «La Catalogne et les Communautés autonomes espagnoles : un modèle pour les "langues de France" ?», Catalonia, nº 14 (2014), p. 13-18 [Disponible en línea], <URL: https:// crimic-sorbonne.fr/wp-content/uploads/2014/06/CATALONIA-14.pdf>.

LLEI 7/1983, de 18 de abril, de normalització lingüística a Catalunya, BOE 11 de mayo de 1983, nº 112 㨚 pág. 13234 殹 y DOGC de 22 de abril de 1983, no 322.

Isidor MARí, «De la normalització a la sostenibilitat: els límits de la planificació de l'estatus», Treballs de Sociolingüística catalana, nํㅡㄴ 21 (2011), p. 83-94.

Isidor MARÍ, «Els usos lingüístics: tres consideraciones sobre la delimitació conceptual, la consolidació i la modificabilitat», Treballs de Sociolingüística Catalana, no 22 (2012), p. 17-26.

Isidre MOLAS, «Los nacionalismos durante la II República. Una perspectiva comparada», Justo Beramendi y Ramón Máiz (comps.), Los nacionalismos en la España de la II República, Madrid, Siglo XXI, 1991, p. 13-23.

Luís MORENO, La federalización de España. Poder político y territorio, Madrid, Siglo XXI, 2008.

Juan Carlos MORENO CABRERA, Los dominios del español: Guía del imperialismo lingüístico panhispánico, Madrid, Síntesis, 2015.

Mercè PUJOL BERCHÉ, Del bilingüismo histórico al plurilingüismo. La inmigración en Cataluña, Habilitation à diriger des Recherches, Perpignan, Université de Perpignan Via Domitia, 2003.

Mercè PUJOL BERCHÉ, «Contribution de l'immigration à la richesse linguistique et culturelle de l'Espagne : réflexions autour de l'intégration sociolinguistique», Marie-Claude Chaput, María Luisa Peñalva y Bruno Tur (eds.), Regards, no 14 (2009), p. 253-270.

Mercè PUJOL BERCHÉ, «Política lingüística: lengua, cultura e identidad, el ejemplo de Cataluña», Amnis, 2013, [disponible le 20 novembre 2013], 熙URL : http://amnis.revues.org/2061医.

Mercè PUJOL BERCHÉ, «Mirades creuades Illes Balears i Catalunya: llengua i política lingüística», Mònica Güell (dir.), Les Illes Balears: Literatura, llengua, història, arts / Les Iles Baléares : Littérature, langue, histoire, arts, Canet, Editions Trabucaire, 2015, p. 47-60. 


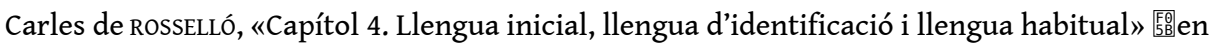
línea蔵, en Direcció General de Política Lingüística, Anàlisi de l'Enquesta d'usos lingüístics de la població a Catalunya 2013. Vol. 1: Coneixements, usos, transmissio i actituds lingüístics, Barcelona, Generalitat de Catalunya. Departament de Cultura. Direcció general de política lingüística. (Biblioteca Tècnica de Política Lingüística, 23. Dades i Estudis), 2018, p. 82-98, 医Consultado el 10.01.2020医, 熙URL: https://llengua.gencat.cat/web/.content/documents/publicacions/btpl/ arxius/23_EULP_Catalunya_2013-vol.1.pdf>.

Joaquim TORRAS-PLA, «L'évolució dels usos privats a Catalunya del 1997 al 2008», Treballs de Sociolingüística Catalana, nํㅡㄹ 22 (2012), p. 27-40.

\section{NOTAS}

1. BASTARDAS et al. consideran que una lengua media es aquella cuyo peso demográfico se sitúa entre los 500.000 y los 25.000 .000 hablantes. Albert BASTARDAS I BOADA, Emili BOIX-FUSTER y Rosa Ma TORRES GUERRINI, El català, llengua mitjana d'Europa. Multilingüisme, globalització $i$ sostenibilitt lingüística, Barcelona, Octaedro, 2018.

2. $\mathrm{M}^{\mathrm{a}}$ Carme JUNYent, Pere COMELlAS, Montserrat CORTÈS-COlomé, Mònica BARRIERAS, Eva MONRÓ y Mònica FIDALGO, La diversidad lingüística: una invitación a reconocerla, comprenderla e incorporarla, Barcelona, Horsori, 2014.

3. IDESCAT, Evolució de la població total i estrangera. 2018, Barcelona, Generalitat de Catalunya, 2019. www.idescat.cat 嚂Consultado el 04.01.2021医.

4. GENERALITAT DE CATALUNYA, Els usos lingüístics de la població a Catalunya. Resultats de l'enquesta d'usos lingüístics de la població 2018, Barcelona, Generalitat de Catalunya. Departament de cultura. Política Lingüística, 2021.

5. Boletín Oficial del Estado. B.O.E. Legislación. Constitución, Madrid, Agencia estatal Boletín Oficial

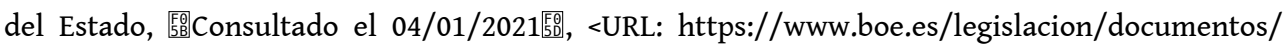
ConstitucionCASTELLANO.pdf>, p. 9.

6. Boletín Oficial del Estado. B.O.E. Legislación. Constitución, Madrid, Agencia estatal Boletín Oficial

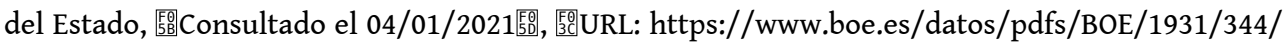
A01578-01588.pdf 医.

7. Isidre MOLAS, «Los nacionalismos durante la II República. Una perspectiva comparada», Justo Beramendi y Ramón Máiz (comps.), Los nacionalismos en la España de la II República, Madrid, Siglo XXI, 1991, p. 13-23.

8. https://www.congreso.es/docu/constituciones/1931/1931_cd.pdf 䜿Consultado el 04/01/2021栭.

9. Daniel CASALS MARTORELL, «Política i planificació lingüístiques durant la Segona República (1931-1939). Els cursos presencials no universitaris de català organitzats i promoguts per la Generalitat de Catalunya», Revista de Llengua i Dret, Journal of Language and Law, nº 74 (2020), p. 58-74, [Disponible en línea], 臨URL: https://doi.org/10.2436/rld.i74.2020.3496>.

10. Alicia FERNÁNDEZ GARCíA y Mathieu PETITHOMME, «Introduction. Du nationalisme d'État aux nationalismes espagnols, la réinvention de la "nation" espagnole depuis la transition démocratique», Alicia Fernández García y Mathieu Petithomme (dirs.), Les nationalismes dans l'Espagne contemporaine (1975-2011). Compétition politique et identités nationales, Paris, Armand Colin, 2012, p. 9.

11. Luís MORENO, La federalización de España. Poder político y territorio, Madrid, Siglo XXI, 2008.

12. Pierre BOURDIEU, Ce que parler veut dire. L'économie des échanges linguistiques, Paris, Fayard, 1982. 
13. Véase Georg KREMNITZ, «Les tensions actuelles entre la Catalogne et l'Espagne», Lengas [En ligne], 79 (2016), [Consultado el 14 noviembre de 2019], <URL: https://journals.openedition.org/ lengas/1040>.

14. Véase Christian LAGARDE, (ed.), Le discours sur les “ langues d'Espagne" / El Discurso sobre las "lenguas españolas" (1978-2008), Perpignan, Presses Universitaires de Perpignan, 2009, sobre el estado de las lenguas cooficiales después de transcurridos treinta años de la Constitución. Véase también Christian LAGARDE, «La Catalogne et les Communautés autonomes espagnoles : un modèle pour les “ langues de France " ? », Catalonia, no 14 (2014), p. 13-18 [en ligne], <URL: https://crimicsorbonne.fr/publication-crimic/catalonia-14/>, sobre el modelo ecolingüístico de las lenguas de España.

15. Juan Carlos MORENo CABRERA, Los dominios del español: Guía del imperialismo lingüístico panhispánico, Madrid, Síntesis, 2015, p. 254.

16. El estatuto del País Vasco no se ha reformado, mientras que el de Andalucía se reformó en el año 2007. Los de Las Islas Baleares y la Comunidad valenciana se han reformado varias veces: en el caso de las Baleares en los años 1994, 1996, 1999 y 2007 y en el caso de la Comunidad valenciana en los años 1991, 1994, 1997, 2002 y 2006. Nos parece interesante recalcar que todos los estatutos de autonomía salvo el del País Vasco se han venido reformando y no solo el de Cataluña, como mucha gente sigue creyendo.

17. Reformado en 1991, 1994, 1997, 20022, 2006 (LO 1/2006, 10 de abril).

18. Reformado en 1994, 1996, 1999, 2007 (LO 1/2007, 28 de febrero).

19. Reforma del Estatuto en 2006 (LO 6/2006, 19 de julio).

20. Sentencia del Tribunal Constitucional 31/2010, de 28 de junio de 2010 (BOE no 172 , de 16 de julio de 2010).

21. Según la Constitución, no puede ser preferente.

22. El subrayado es nuestro.

23. Boletín Oficial del Estado. B.O.E. Legislación. Constitución, Madrid, Agencia estatal Boletín Oficial del Estado. BOE no 172 de 20 de julio de 2006, [en línea], [50 [0RL: https://www.boe.es/buscar/ act.php?id=BOE-A-2006-13087\#>.

24. Llei 7/1983, de 18 de abril, de normalització lingüística a Catalunya, BOE 11 de maig de 1983, nº 112, p. 13234, y DOGC de 22 de abril de 1983, no 322.

25. Véase Isidor MARÍ, «De la normalització a la sostenibilitat: els límits de la planificació de l'estatus», Treballs de Sociolingüística catalana, nº 21 (2011), p. 83-94.

26. Véanse Mercè PUJOL BERCHÉ, «Contribution de l'immigration à la richesse linguistique et culturelle de l'Espagne: réflexions autour de l'intégration sociolinguistique», Marie-Claude Chaput, María Luisa Peñalva y Bruno Tur (eds), Regards, no 14 (2009), p. 253-270, y Mercè PujoL BERCHÉ, «Mirades creuades Illes Balears i Catalunya: llengua i política lingüística», Mònica Güell (dir.), Les Illes Balears: Literatura, llengua, història, arts / Les Iles Baléares : Littérature, langue, histoire, arts, Canet, Éditions Trabucaire, 2015, p. 47-60.

27. Véase Josep GIFREU, «Procés de normalització del català en els mitjans de comunicació: notes sobre l'evolució de la recerca, 1980-2010», Treballs de Sociolingüística Catalana, oㅡ 21, 2011, p. 73-82. 28. IDESCAT (2019). Evolució de la població total i estrangera. 2018, <URL: www.idescat.cat>.

29. $M^{a}$ Carme JUNYent, Pere COMEllas, Montserrat CORTÈs-COlOME, Mònica BARRIERAS, Eva MONRó y Mònica FIDALGO, La diversidad lingüística: una invitación a reconocerla, comprenderla e incorporarla, Barcelona, Horsori, 2014.

30. Mercè PUJOL BERCHÉ, Del bilingüismo histórico al plurilingüismo. La inmigración en Cataluña, Habilitation à diriger des Recherches, Perpignan, Université de Perpignan Via Domitia, 2003.

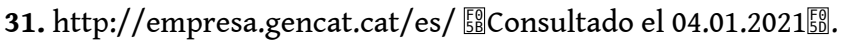


32. Francesc bernat, Mireia GALINDo y Carles de Rosselló, «Des de quan som bilingües els catalans», Apunts de sociolingüística i política lingüística, $\mathrm{n}^{-}$7, CUSC (Centre de recerca en sociolingüística i comunicació), Barcelona, Universitat de Barcelona, 2019, p. 1-4.

33. Isidor MARí, «Els usos lingüístics: tres consideraciones sobre la delimitació conceptual, la consolidació i la modificabilitat», Treballs de Sociolingüística Catalana, oㅡ 22 (2012), p. 17-26.

34. Jean-Claude CORBEIL, L'aménagement linguistique du Québec, Montreal, Guérin, 1980.

35. Albert BASTARDAS, «Comunicacions institucionalitzades i comunicacions individualitzades: la complexitat de l'ús social de les llengües», Treballs de Sociolingüística Catalana, no 17 (2003), p. 315-322.

36. Isidor MARí, «Els usos lingüístics: tres consideraciones sobre la delimitació conceptual, la consolidació i la modificabilitat», Treballs de Sociolingüística Catalana, ํㅡㄹ 22 (2012), p. 17-26.

37. Op. cit.

38. Albert FABÀ PRATS, «L'evolució dels usos professionals a Catalunya del 1997 al 2008», Treballs de Sociolingüística Catalana, nำ 22, 2012, p. 41-58.

39. La población es la que corresponde al registro de la población en Cataluña. GENERALITAT DE CATALUNYA, Els usos lingüístics de la població a Catalunya. Resultats de l'enquesta d'usos lingüístics de la població 2018, Barcelona, Generalitat de Catalunya. Departament de cultura. Política Lingüística, 2021.

40. Véanse DIRECCIÓ GENERAL DE POLÍTICA LINGÜÍSTICA (DGPL), Enquesta lingüística sobre l'ús oral del català entre la població de Catalunya major de 15 anys: Informe i resum, Barcelona, Generalitat de Catalunya, 1998; DIRECCIÓ GENERAL DE POLÍTICA LINGÜÍSTICA (DGPL), Accions. Barcelona, Generalitat de Catalunya, 2010; DIRECCIÓ GENERAL DE POLÍTICA LINGÜÍsTICA (DGPL), Enquesta d'usos lingüístics de la població 2008. Anàlisi. Volum I: Les llengües a Catalunya: coneixements, usos, transmissió $i$ actituds lingüístics. Barcelona, generalitat de Catalunya, 2011, [Disponible en línea], <URL: https:// llengua.gencat.cat/permalink/2e24ce66-5384-11e4-8f3f-000c29cdf219>; GENERALITAT DE CATALUNYA, Perfil sociodemogràfic dels col-lectius més nombrosos a Catalunya. Xifres provisionals a 1 de gener de 2013. Barcelona, Departament de Benestar Social i Família, Direcció General per a la immigració, 2012.

41. En 2003, la encuesta se llamó Enquesta d'Usos lingüístics a Catalunya (EULC, 2003) y a partir de 2008 se denominó Enquesta d'Usos Lingüístics a la Població de Catalunya (EULP, 2008).

42. La muestra en la encuesta de 2013 fue de 7.500 individuos.

43. IDESCAT, Evolució de la població total i estrangera. 2018, Generalitat de Catalunya, 2019. [0] URL: www.idescat.cat>.

44. Véase el balance que se hace de dichas campañas entre 1997 y 2010 en el artículo de Josep Maria AYMÀ AUBEYZON, «Els usos interpersonals o privats a Catalunya. Balanç i perspectives de futur», Treballs de Sociolingüística Catalana, no 22 (2012), p. 59-72.

45. Albert BASTARDAS I BOADA, Emili BOIX-FUSTER y Rosa M ${ }^{a}$ TORRES GUERRINI, El català, llengua mitjana d'Europa. Multilingüisme, globalització i sostenibilitt lingüística, Barcelona, Octaedro, 2018.

46. Fórmula consagrada por el antiguo presidente de la Generalitat Jordi Pujol cuando desde el punto de vista político él y su partido necesitaban definir quién era catalán (el que vivía y residía en Cataluña).

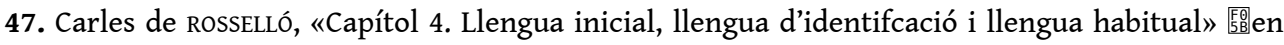
línea藻, en Direcció General de Política Lingüística, Anàlisi de l'Enquesta d’usos lingüístics de la població a Catalunya 2013. Vol. 1: Coneixements, usos, transmissio i actituds lingüístics, Barcelona, Generalitat de Catalunya. Departament de Cultura. Direcció general de política lingüística. (Biblioteca Tècnica de Política Lingüística, 23. Dades i Estudis), 2018, p. 82-98, 䜿Consultado

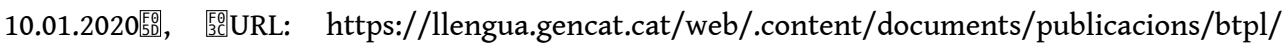
arxius/23_EULP_Catalunya_2013-vol.1.pdf医.

48. Joaquim toRRAS-PLA, «L'évolució dels usos privats a Catalunya del 1997 al 2008», Treballs de Sociolingüística Catalana, $\mathrm{n}^{\circ} 22$ (2012), p. 27-40. 
49. https://elpais.com/elpais/2008/06/23/actualidad/1214209045_850215.html 檪Consultado el 04.01 .2021 喝.

50. Sobre el alboroto mediático que dicho Manifiesto causó, véase Chrystelle BURBAN, « Le buzz médiatique médiatique dans Manifiesto por la lengua común ", Christian Lagarde (ed.), Le discours sur les "langues d'Espagne" / El discurso sobre las "lenguas de España", Perpignan, Presses Universitaires de Perpignan, 2009, p. 255-268.

51. Carles de Rosselló, «Capítol 4. Llengua inicial, llengua d'identifcació i llengua habitual» 䜿en línea熙, en Direcció General de Política Lingüística, Anàlisi de l'Enquesta d'usos lingüístics de la població a Catalunya 2013. Vol. 1: Coneixements, usos, transmissio i actituds lingüístics, Barcelona, Generalitat de Catalunya. Departament de Cultura. Direcció general de política lingüística. (Biblioteca Tècnica de Política Lingüística, 23. Dades i Estudis), 2018, p. 82-98. 熙Consultado el 10.01.2020医, 溥URL: https://llengua.gencat.cat/web/.content/documents/publicacions/btpl/ arxius/23_EULP_Catalunya_2013-vol.1.pdf>.

52. Barcelona, Àrea metropolitana de Barcelona, 嘼Consultado el 08.01.2021熙, <URL: https:// www.amb.cat/s/web/area-metropolitana/coneixer-l-area-metropolitana/activitateconomica.html>.

53. 獸Consultado el 08.01.2021監, <URL: https://www.amb.cat/s/web/area-metropolitana/ coneixer-l-area-metropolitana/activitat-economica.html>.

54. Mercè PUJOL BERCHÉ, «Política lingüística: lengua, cultura e identidad, el ejemplo de Cataluña»,

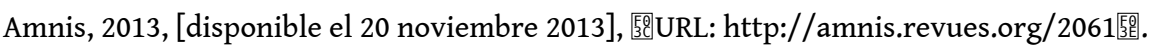

55. IDESCAT, EULP. Enquesta d'usos lingüístics de la població, Generalitat de Catalunya, 配URL: https://www.idescat.cat/pub/?id=eulp>.

56. Op. cit.

57. Mercè PUJOL BERCHÉ, «Mirades creuades Illes Balears i Catalunya: llengua i política lingüística», Mònica Güell (dir.), Les Illes Balears: Literatura, llengua, història, arts / Les Iles Baléares : Littérature, langue, histoire, arts, Canet, Editions Trabucaire, 2015, p. 47-60.

58. Mercè PUJOL BERCHÉ, «Mirades creuades Illes Balears i Catalunya: llengua i política lingüística», op. cit.

59. Op. cit.

60. Fina ANTÓN HURTADO y Claudio MATTARAZO, «Invirtiendo la ruta del proceso de retorno de los ecuatorianos en España», Universitas, XIII, nº 23 (2015), p. 35-64.

61. Mercè PUJOL BERCHÉ, «Mirades creuades Illes Balears i Catalunya: llengua i política lingüística», op. cit.

62. Albert FABÀ PRATS, «L'evolució dels usos professionals a Catalunya del 1997 al 2008», Treballs de Sociolingüística Catalana, nº 22 (2012), p. 41-58.

63. Mercè PUJOL BERCHÉ, «Mirades creuades Illes Balears i Catalunya: llengua i política lingüística», Mònica Güell (dir.), Les Illes Balears: Literatura, llengua, història, arts / Les Iles Baléares : Littérature, langue, histoire, arts, Canet, Editions Trabucaire, 2015, p. 47-60.

64. Los datos obtenidos son de una población de 6.386 individuos.

65. IDESCAT, EULP. Enquesta d'usos lingüístics de la població, Generalitat de Catalunya, 庖URL: https://www.idescat.cat/pub/?id=eulp> .

66. Nuestra traducción. Albert FABÀ PRATS y Joaquim TORRES-PLA, «De la llengua inicial a la llengua d'identificació a Catalunya: qui adopta el català i qui se n'allunya», Treballs de Sociolingüística catalana, nº 30 (2012), p. 231. 


\section{RESÚMENES}

Après avoir mis en contexte le statut des langues co-officielles en Catalogne et présenté la composition de la population étrangère dans cette communauté autonome, l'article expose les résultats de l'enquête sur l'emploi des langues de la population réalisée en 2018. De manière globale, la Catalogne est passée d'être une société bilingue à une société multilingue. En ce qui concerne le catalan, il est la langue habituelle de $36,4 \%$ de la population. Ce pourcentage est stable par rapport aux résultats observés lors de l'enquête de 2013. Le pourcentage se décline sur un continuum qui va de l'agglomération métropolitaine (27,5\%) aux Terres de l'Èbre (72,2 \%). Au sein des foyers, le castillan est la langue majoritaire choisie comme habituelle. Seulement 7,2 \% de la population dit employer les deux langues dans la sphère privée, tel que le foyer, tandis que $4,9 \%$ dit n'utiliser ni le castillan, ni le catalan. Presque la moitié des enquêtés (46,6 \%) déclare avoir le castillan comme langue habituelle avec les voisins, tandis que $4 \%$ de la population dit n'employer aucune des deux langues co-officielles. Au vu des données, le catalan n'est pas en train de déplacer le castillan, comme il est souvent déclaré par des collectifs hispanophones.

After presenting the context of the status of co-official languages in Catalonia and the breakdown of the foreign population in the autonomous community, this article exposes the results of a study carried out in 2018 on language use. In general, Catalonia has gone from a bilingual society to a multilingual society. As far as Catalan goes, it is the habitual language of $36.4 \%$ of the population, a constant percentage in relation to results of a 2013 study. There are regional fluctuations from the metropolitan area (27.5\%) to the Terres de l'Ebre (72.2\%). As for households, Castilian is the customary language for the majority. Only $7.2 \%$ of the population say they use both languages in a private setting such as at home, whereas $4.9 \%$ say they use neither Catalan or Castilian. Almost one half of those polled, (46.6\%) state habitually using Castilian with neighbors, whereas $4 \%$ say they use neither of the two co-official languages. These data show that Catalan is not replacing Castilian, as is often claimed by Spanish speaking organizations.

\section{ÍNDICE}

Keywords: linguistic study, co-official languages, Catalonia, habitual language, use of languages Mots-clés: enquête linguistique, langues co-officielles, Catalogne, langue habituelle, emploi des langues

\section{AUTOR \\ MERCÉ PUJOL BERCHÉ}

Université de Perpignan Via Domitia, CRESEM, EA 7379 